In 8-week or 6-month stored hams, the taste panel did not notice any important difference according to the cereal either on lean or on fat (no rancid taste).

It may be concluded that monocereal diets (soyabean meal) have little effect on lean. As regards the fat, maize diets lead to a higher unsaturated fatty acid content of fat than wheat or barley diets, although the levels have no effect on the organoleptic qualities according to the taste panel.

\title{
Meat production from entire male pigs : Performance, meat quality and alternatives to boar taint
}

\author{
M. BONNEAU \\ Institut National de la Recherche Agronomique, Station de Recherches Porcines, \\ Saint-Gilles, 35590 L'Hermitage
}

The chemical composition of meat from entire male pigs is slightly different from that of castrates. The higher unsaturated fatty acid content of boar meat may be a drawback for some processed products. However, the main problem is boar taint. The latter is mainly due to the presence of skatole and androstenone responsible for the odour of faeces and urine, but the respective contribution of these compounds is still poorly understood.

Tainted meat may be used for processing. There is no entirely satisfactory method for sorting tainted meats on the slaughter line. A preliminary screening is possible using the measurement of Cowper's gland development. In some cases, such a screening might enable an increase in boar meat production. At the present time, there is no means of producing boars that could be certified as taint-free. Genetic and immunology offer promising ways of getting rid of the boar taint problem : further research is needed for an adaptation of these methods from the laboratory to the industry scale.

\section{GÉNÉTIQUE - GENETICS}

\section{Chromosomal abnormalities and " hypoprolificacy "}

\author{
P. POPESCU ${ }^{(1)}$, C. LEGAULT $^{(2)}$ \\ (1) Station de Cytogénétique; (2) Station de Génétique quantitative et appliquée \\ Institut de Recherche Agronomique. Centre de Jouy-en-Josas, Domaine de Vilvert, \\ 78350 Jouy-en-Josas
}

Owing to the great amount of research done in human medicine, the applications of cytogenetics in domestic mammals have spread out in the last decade. Following a brief survey of the methods which allow a more and more precise identification of chromosomes, this review is intended to give an overall presentation of porcine chromosomal abnormalities found in France and in the world, with special emphasis on their economic consequences and the means available for limiting their diffusion. In France, periodical analysis of data from the National Programme for Computerized Sow Herd Management allows to detect the so-called «hypoprolific » boars having sired litters whose average size of at least 6 litters is less than 8 piglets born alive. The proportion of these «suspected » boars among all breeding boars is about $1 / 1000$, and among those subjected 